\title{
Vertigo and dizziness in elderly patients with neurological disorders
}

\author{
Vertigens e tonturas em pacientes idosos com distúrbios neurológicos
}

\author{
Pedro Luiz Mangabeira Albernaz ${ }^{1}$, Flávia Silveira dos Santos Cabral ${ }^{2}$
}

\begin{abstract}
Objective: To evaluate the frequency of central vestibular disorders, vertigo and dizziness in patients aged 65 to 90 years. Methods: We analyzed 735 patients in this age range seen consecutively from January 1990 to December 2009. Results: A total of 32 patients had central vestibular disorders, and 11 had neurological disorders diagnosed by imaging. Conclusion: Vertigo and dizziness occur frequently in elderly people with neurological disorders, and affect their quality of life. Falling is common and may lead to disabling consequences.
\end{abstract}

Keywords: Vestibular diseases/etiology; Nervous system diseases; Dizziness; Accidental falls; Aged; Aged, 80 and over

\section{RESUMO}

Objetivo: Avaliar a frequência de afecções vestibulares centrais em pacientes com 65 a 90 anos de idade e com vertigens ou tonturas. Métodos: Análise de 735 pacientes nessa faixa etária examinados sequencialmente de janeiro de 1990 a dezembro de 2009. Resultados: Dos pacientes, 32 apresentaram afecções vestibulares centrais; 11 outros apresentaram afecções neurológicas diagnosticadas por imagem. Conclusão: A vertigem e as tonturas ocorrem frequentemente em pacientes idosos com distúrbios neurológicos e afetam sua qualidade de vida; quedas são comuns e podem levar a sérias consequências.

Descritores: Doenças vestibulares/etiologia; Doenças do sistema nervoso; Tontura; Acidentes por quedas; Idoso; Idoso de 80 anos ou mais

\section{INTRODUCTION}

Clinical manifestations of vestibular disorders in elderly patients are considered to be closely related to the aging process. In healthy elderly people, however, these disorders are less frequent when compared with those with vascular, metabolic or degenerative diseases, or with neurological conditions that affect the central vestibular pathways ${ }^{(1)}$.

Vestibular disorders in elderly patients are clinically important, and have drawn attention of many investigators $^{(2-9)}$.

\section{OBJECTIVE}

To evaluate the frequency of central vestibular disorders, vertigo and dizziness in patients aged 65 to 90 years.

\section{METHODS}

This is a retrospective study of a group of consecutively analyzed patients seen in a private clinic that complained of vertigo or dizziness, and had neurological disorders. The study was approved by the Ethics Committee of Hospital Israelita Albert Einstein in São Paulo (SP), Brazil, CAAE - 0117.0.028.000-10.

A total of 735 patients aged 65 to 90 years were consecutively examined from January 1990 through December 2009 at a private otolaryngology clinic presenting as the most frequent clinical complaints hearing loss, respiratory problems and vestibular disorders. A detailed clinical history of each patient was obtained, and then they were submitted to a complete otolaryngological examination, followed by audiological and vestibular tests. Audiological tests included pure tone audiometry, speech reception and discrimination scores. Immittance tests were done when deemed necessary. In some patients auditory brainstem responses were also obtained.

\footnotetext{
Study carried out at Hospital Israelita Albert Einstein - HIAE, São Paulo (SP), Brazil.

${ }^{1}$ Escola Paulista de Medicina, Universidade Federal de São Paulo - UNIFESP; Hospital Israelita Albert Einstein - HIAE, São Paulo (SP), Brazil.

2 Otoneuroclinica Serviços Médicos - Ltda - São Paulo (SP), Brazil.

Corresponding author: Pedro Luiz Mangabeira Albernaz - Avenida Albert Einstein, 627/701 consultório 117 B BI. A1 - Jardim Leonor - CEP $05651-901$ - São Paulo (SP), Brazil - Tel.: 11 2151-9717 E-mail: albernaz@einstein.br

Received on: Jun 4, 2011 - Accepted on: Oct 28, 2011

Conflict of interest: none
} 
The vestibular test included the following: Romberg test, gait and cerebellar tests, evaluation of spontaneous and semi-spontaneous nystagmus, Hallpike maneuvers for postural vertigo, pendular eyetracking, evaluation of optokinetic nystagmus, torsion swing tests, and caloric tests using the Hallpike two-temperature technique.

Nystagmus was recorded with a three-channel device using the vector-nystagmography technique developed by Padovan and Pansini ${ }^{(10,11)}$. Exception was given for the tests of dissociated nystagmus, which employed two channels, one for each eye ${ }^{(12)}$. Laboratory tests were ordered when necessary.

All patients were submitted to computed tomography scan or to magnetic resonance imaging or both. These tests were done before or after the neurotological tests.

\section{RESULTS}

The number of patients with imbalance and/or vertigo was 162, $69(42.6 \%)$ were men and $93(57.4 \%)$ were women (22.3\% of the total). Central vestibular findings occurred in 32 patients $(19.5 \%)$, and 11 patients $(6.7 \%)$ had neurological disorders as diagnosed by imaging. Three patients presenting minor central disorders of metabolic origin, and who had bouts of hypoglycemia because of medication for diabetes were excluded. The age of 40 patients of this population with neurological disorders ranged from 65 to 81 years being the mean age 75.6 , with a standard deviation of 7.65 and 22 of them were women.

Eight patients presented significant prodromic signs: two patients had cerebral vascular accidents, other two had meningiomas; cerebellar tumor treated by stereotactic radio-surgery, or sequel of meningitis, or ovarian carcinoma (treated with chemotherapy) or agranulocytosis were presented by at least one patient each.

\section{Audiological findings}

All patients had sensorineural hearing loss in variable degrees. After the audiograms were corrected for the patient's ages according to Glorig \& Davis normal agerelated averages ${ }^{(13)}$, and 9 of them $(22.5 \%)$ had normal hearing for their age. A high frequency loss more intense than the Glorig and Davis averages was observed in 23 patients $(57.5 \%)$.

The speech discrimination scores were within the expected ranges except for one patient who had abnormally low scores $(2.5 \%)$.

\section{Vestibular findings}

The vestibular evaluation showed normal responses for 9 patients $(22.5 \%) ; 12(30.0 \%)$ had symmetrical vestibular hyperflexia; 9 (22.5\%) presented bilateral hyporeflexia; $7(17.5 \%)$ unilateral hyporeflexia; 2 patients $(5.0 \%)$ had unilateral vestibular areflexia and bilateral areflexia was found in 1 patient $(2.5 \%)$. Horizontal spontaneous nystagmus was seen in 9 patients $(22.5 \%)$.

The central vestibular signs observed in these patients were: dissociated nystagmus (12 patients, 30.0\%), semispontaneous nystagmus in different directions of the gaze (4 patients, $10.0 \%$ ), vertical spontaneous nystagmus (3 patients, $7.5 \%$ ), bilateral horizontal semispontaneous nystagmus (3 patients, $7.5 \%$ ), alternating spontaneous nystagmus ( 2 patients, $5.0 \%$ ), absent fixation effect with eyes opened, vestibular decruitment (torsion swing responses smaller in amplitude than caloric responses), perverted nystagmus and inverted nystagmus (1 patient each, 2.50\%). Most of the patients presented associations with several central signs.

\section{Diagnostic categories}

The diagnostic categories of the 40 patients with neurological disorders and vertigo are described in table 1.

Table 1. Elderly patients with neurological disorders and vertigo

\begin{tabular}{lcc}
\hline Neurological disorders & $\mathbf{n}$ & $\%$ \\
\hline Degenerative disorders & 19 & 47.5 \\
Hydrocephalus ex-vacuo & 8 & 20.0 \\
Use of diuretics & 4 & 10.0 \\
Use of beta-blockers & 2 & 5.0 \\
Vascular disorders & 2 & 5.0 \\
Basilar artery insufficiency & 2 & 5.0 \\
Meningioma of temporal lobe & 1 & 2.5 \\
Diffuse encephalopathy & 1 & 2.5 \\
Cerebral cysticercosis & 1 & 2.5 \\
\hline Total & 40 & 100.00 \\
\hline
\end{tabular}

In $11(27.5 \%)$ patients the diagnosis was established by computed tomography scans and/or by magnetic resonance imaging. Nine patients $(22.5 \%)$ had vestibular tests devoid of characteristic central signs.

A total of 13 patients had falls $(32.5 \%)$, and 1 of them fell several times. From this total, three had fractures, two having broken the femur neck, requiring prostheses, and one patient had fractured a dorsal vertebra.

Two patients had repeated drop attacks and four reported episodes of loss of conscience for short intervals.

\section{DISCUSSION}

In this population of 735 patients of 65 or older, approximately $20 \%$ presented vestibular disorders. 
Forty of these patients had neurological disorders and vertigo.

This percentage is significantly lower than that of other studies, which vary from 45 to $65 \%{ }^{(2-5)}$. A possible explanation for this might be that these patients belong to a social group with easy access to health care, and they are more concerned with their health conditions than most of the general population.

The vestibular tests were conducted using the vector-nystagmography technique, with three separate channels ${ }^{(11,12)}$. This technique allows an accurate measure of the speed of the slow component of nystagmus and is capable of recording rotatory eye movements as oblique vectors.

The evaluation of the vestibular tests allowed the identification of central vestibular disorders, which are characterized by different signs. These are the only tests that verify the function of the reticular formation in the posterior fossa. Some patients referred by neurologists had been previously submitted to computed tomography scan or magnetic resonance imaging and some of them presented normal vestibular tests. It has been demonstrated that the vestibular examination is very sensitive to diagnose posterior fossa disorders, but less sensitive to supratentorial lesions ${ }^{(14)}$.

It must be emphasized that vestibular tests are functional and may detect central disturbances not shown in imaging tests. Therefore, they are important for elderly people with imbalance. It is a known fact that some physicians do not order vestibular tests for their patients to avoid causing them discomfort but such attitude may multiply the patients' problems ${ }^{(2)}$. An attempt was made to determine the etiology of the vestibular disorder whenever possible, so the patients were categorized by their diagnosis rather than by the results of their vestibular tests.

Approximately one half of the patients in this study had degenerative diseases of the central nervous system. The recognition of dissociated nystagmus ${ }^{(12)}$ was important to the diagnosis of these problems, since qualitative nystagmus dissociation is related to lesions of the medial longitudinal fasciculus and isquite common, although not pathognomonic in degenerative central nervous system disorders.

Hydrocephalus ex-vacuo is fairly common in elderly patients and is often associated to imbalance, not to vertigo. One patient who was indicated for a low-pressure ventricular shunt obtained relief from symptoms.

The use of diuretics and beta-blockers to control blood pressure may cause central vestibular disturbances due to reduced cerebral blood flow. Actually all medications for hypertension reduce the cerebral blood flow $^{(15,16)}$, but diuretics and beta-blockers are the ones most frequently associated with orthostatic hypotension and vertigo in elderly patients. These symptoms rarely occur in young population.

Two patients had basilar artery insufficiency, and the remaining ones presented a temporal lobe meningioma, a vestibular schwannoma, a diffuse encephalopathy and a cerebral cysticercosis.

\section{Falls}

Vestibular disorders in elderly people reduce their postural controls, affecting their gait and their transitional activities, such as moving from a supine to a sitting position, or from sitting to standing ${ }^{(17)}$.

Falls are common among these patients. According to orthopedists evaluation, approximately $60 \%$ of them falling accidentally, $20 \%$ from neurological disturbances and another $20 \%$ from vestibular disorders. Falls make patients feel insecure and reflect in their quality of life, with consequences to their general health condition. They also contribute to elevate the costs of medical treatment. Consequently, the diagnosis and treatment of vestibular disorders in elderly patients are of the utmost importance in order to maintain their quality of life.

In this group of patients the frequency of fall was significantly lower than the numbers reported in other studies ${ }^{(3-8)}$. This may be attributed to the health care, social and economical status among this population.

Many drugs available nowadays to modern Medicine can effectively block, stimulate vestibular function, improve the inner ear circulation, correct metabolic problems, or stabilize auto-immune disorders. The careful selection of these drugs will depend on an equally careful diagnosis. Vestibular rehabilitation may be very useful in the treatment of vestibular problems in elderly patients.

Elderly people often present imbalance and/or vertigo, which must be diagnosed and treated. This diagnosis depends on a careful clinical history and neurological examination complemented by laboratory tests and imaging when needed.

The medications used by such patients have to be carefully evaluated, mainly because they can induce or intensify vestibular symptoms.

Besides prescribing an adequate treatment, physicians must take into consideration the use of vestibular rehabilitation that is of great value for elderly patients in preventing falls and maintaining a good quality of life. 


\section{CONCLUSION}

The comparison of this series of patients with others in the medical literature suggests that the concern with health and access to medical treatment may reduce the percentage of serious vestibular disorders and falls, particularly in patients with imbalance associated with neurological disorders.

\section{REFERENCES}

1. Mangabeira-Albernaz PL. Aspectos otoneurológicos da velhice. Acta AWHO. 1982;1(3):93-5.

2. Garcia FV. Disequilibrium and its management in elderly patients. Int Tinnitus J. 2009;15(1):83-90.

3. Siqueira FV, Facchini LA, Piccini RX, Tomasi E, Thumé E, Silveira DS, et al. Prevalência de quedas em idosos e fatores associados. Rev Saude Publica. 2007; $41(5): 749-56$.

4. Levencron S, Kimyagarov S. Frequency and reasons for falling among residents of a geriatric center. Harefuah. 2007;146(8):589-93, 647.

5. Bouras T, Stranjalis G, Korfias S, Andrianakis I, Pitaridis M, Sakas DE. Head injury mortality in a geriatric population: differentiating an "edge" age group with better potential for benefit than older poor-prognosis patients. J Neurotrauma. 2007;24(8):1355-61.

6. Ganança FF, Gazzola JM, Aratani MC, Perracini MR, Ganança MM. Circunstâncias e conseqüências de quedas em idosos com vestibulopatia crônica. Rev Bras Otorrinolaringol. 2006;72(3):388-93.
7. Liu B, Liu C, Chen XW, Duan JP, Zhao XY, Guan JZ, et al. Investigation and analysis of the baseline data of 3432 patients with vertigo. Zhongguo Yi Xue Ke Xue Yuan Xue Bao. 2008;30(6):647-50.

8. Katsarkas A. Dizziness in aging: the clinical experience. Geriatrics. 2008;63(11):18-20.

9. Walther LE, Nikolaus T, Schaaf H, Hörmann K. Vertigo and falls in the elderly. Epidemiology, pathophysiology, vestibular diagnostics and risk of falling. HNO. 2008;56(8):833-41.

10. Padovan I, Pansini M. New possibilities of analysis in electronystagmography. Acta Oto-laryngol (Stockh). 1972;73(2):121-5.

11. Mangabeira-Albernaz PL, Ganança MM, Caovilla HH, Ito Yl, Castro HD. Atlas de vecto-electronistagmografia. São Paulo: Aché; 1984.

12. Mangabeira-Albernaz PL. Dissociated eye movements. Acta Otolaryngol (Stockh). 2005;125(5):495-8.

13. Glorig A, Davis H. Age, noise and hearing loss. Ann Otol Rhinol Laryngol. 1961;70:556-74.

14. Mangabeira-Albernaz PL, Ganança MM. Vertigem. 2a ed. São Paulo: Moderna; 1976.

15. Fagan SC, Ewing JR, Levine SR, Tietjen GE, Ramadan NM, Welch MA. Assessing the effects of antihypertensive medication on cerebral blood flow: demonstrations in internal carotid artery occlusion. DICP A. 1991;25(12): 1299-301.

16. Mangabeira Albernaz PL. Diuréticos como causadores de vertigens centrais. Acta AWHO. 1989;8:128

17. Mira E. Improving the quality of life in patients with vestibular disorders: the role of medical treatments and physical rehabilitation. Int $\mathrm{J}$ Clin Pract. 2008;62(1):109-16. 